\title{
PERHITUNGAN KERUGIAN ENERGI PADA PENYULANG TAMBAK LOROK-03 SEBAGAI SALAH SATU PILOT PROJECT PROGRAM REVASS (REVENUE ASSURANCE) DALAM PROGRAM REKONSILIASI ENERGI PT. PLN (PERSERO) AREA SEMARANG
}

\author{
Ruri Diana Putranti, Iman Setiono \\ Program Studi Diploma III Teknik Elektro \\ Fakultas Teknik Universitas Diponegoro
}

\begin{abstract}
Ruri Diana Putranti, Iman Setiono, in paper calculation of energy losses of Tambak Lorok - 03 feeder as one of the pilot project program REVASS (revenue assurance) in energy reconciliation program of $P T$ . PLN (persero) semarang area explain that in an electric power system there is a factor called the loss factor or energy depletion. This shrinkage can be found in various places on the electricity network, from generation, transmission and distribution of both to consumers. The release of energy or commonly referred to as shrinkage , the harm to the company for commercial and service in large and small quantities. Pond feeder Lorok - 03 is one of the feeders are thought to have a large enough energy depletion. This feeder is in the working area of PT . PLN Rayon East Semarang and is a feeder into the pilot established REVASS ( Revenue Assurance) PT . PLN Semarang area. Based on mathematical calculations that have been carried out in February 2013 the amount of power loss in the feeder is 2,316,319 KWH, while in the month of March 2013 is 4,765,637 KWH and in April 2013 amounted to 18,809,238 KWH. The amount of power loss raises the average monthly percentage losses in the feeder that is between 10-20\%. This of course lead to a loss for the company, especially on the commercial side that is the size of the company to the customer's receivables. Therefore, a program in which reconciliation is REVASS this project, is one attempt to get the suitability amount of energy from the power sent to the power received at the customer .
\end{abstract}

Keywords : Electric Power System , Network Distribution, Energy Losses, Reconciliation of Energy

\section{PENDAHULUAN \\ Latar belakang}

Terjadinya susut energi mengakibatkan kerugian baik secara teknis maupun non teknis bagi PT. PLN (Persero) yang dimana kerugian sejumlah energi ini berdampak pada ketidaksesuaian pendapatan perusahaan dari penjualan energi listrik dengan energi listrik yang sudah tersalurkan. Usaha untuk mengatasi susut energi telah dilakukan secara terus menerus dan sebagai indikatornya dilakukan pengawasan dan evaluasi terhadap besaran susut dari waktu ke waktu dengan menggunakan presentasi besaran susut yang diperoleh dari perhitungan susut.

Indikator perusahaan listrik kelas dunia salah satunya adalah susut (losses). Jika ingin diakui sebagai perusahaan kelas dunia, maka susut jaringan maksimal adalah 5\%, sedangkan perlu diketahui bahwa susut KEPCO (Korea Electric Power Corporation) nilainya sebesar 4,8 \%, maka jelas dalam hal ini PLN masih jauh tertinggal.

Berdasarkan Aplikasi Susut PT. PLN (Persero) disebutkan bahwa pada bulan Januari 2013 susut di Rayon Semarang Timur sebesar 12,27\%. Sedangkan untuk bulan Februari - April angka susut untuk Rayon Semarang Timur berkisar antara 8,6\%. Maka jika dibandingkan dengan 9 Rayon lain di Area Semarang, susut di Rayon Semarang Timur merupakan salah satu yang tertinggi di antara lainnya. Tingginya angka susut energi di Rayon Semarang Timur disebabkan oleh faktor teknis maupun non teknis, namun berdasarkan data survey yang telah dilakukan oleh tim Pelayanan Teknik, susut terbesar di Rayon Semarang Timur disebabkan oleh hal-hal yang bersifat non teknis. Penyebab susut secara teknis hanya bekisar 5\% saja dari jumlah total susut.

REVASS (Revenue Assurance) atau dalam Bahasa Indonesia bisa disebut dengan perang bocor merupakan suatu program unggulan PLN untuk memerangi kebocoran (susut) energi maupun pendapatan. Sejumlah kwh yang hilang (susut) itu merupakan uang pendapatan perusahan yang menjadi hilang akibat bocor secara teknis dan non teknis. Dalam hal ini, Rayon Semarang Timur merupakan salah satu fokus utama program REVASS PT. PLN (Persero) Area Semarang dikarenakan tingginya angka susut energi di wilayah tersebut.

\section{Perumusan Masalah}

Masalah-masalah yang akan dibahas dan dianalisa dalam penelitian ini adalah :

- $\quad$ Total jumlah energi yang hilang dari main feeder Tambak Lorok-03 ke trafo distribusi lalu trafo distribusi sampai dengan pelanggan.

- Model perhitungan susut yang dilakukan untuk mengetahui sejumlah energi yang hilang dari titik penyulang sampai dengan ke pelanggan. 
- $\quad$ Penyebab tingginya susut energi pada penyulang Tambak Lorok-03.

- Pelaksanaan program perbaikan susut energi pada penyulang Tambak Lorok-03.

\section{LANDASAN TEORI}

Sistem penyaluran tenaga listrik yang secara teori disebut sebagai Sistem Tenaga Listrik memiliki pengertian sebagai suatu kesatuan dari unit pembangkit listrik, unit transmisi listrik, dan unit distribusi listrik yang menyalurkan energi listrik dari produsen (energi listrik dibangkitkan) hingga sampai ke pelanggan. Ada tiga bagian penting dalam proses penyaluran tenaga listrik, yaitu pembangkitan, penyaluran (transmisi) dan distribusi.

Disisi lain, terpenuhinya energi listrik dari pembangkitan sampai ke pelanggan terjadi beberapa kebocoran yang biasa disebut dengan susut. Susut energi terkadang hanya dihitung skala maksimal yaitu pada tingkat rayon, sedangkan perhitungan susut per-penyulang masih jarang dilakukan karena sulitnya manajemen aset serta pendataan yang ada di penyulang tersebut.

\section{Sistem Distribusi Tenaga Listrik}

Sistem Distribusi merupakan bagian dari sistem tenaga listrik. Sistem distribusi ini berguna untuk menyalurkan tenaga listrik dari sumber daya listrik besar (Bulk Power Source) sampai ke konsumen. Jadi fungsi distribusi tenaga listrik adalah:

- Pembagian atau penyaluran tenaga listrik ke beberapa tempat (pelanggan)

- Merupakan sub sistem tenaga listrik yang langsung berhubungan dengan pelanggan, karena catu daya pada pusat-pusat beban (pelanggan) dilayani langsung melalui jaringan distribusi.

\section{Bagian Distribusi dan Beban Gardu Induk}

Gardu induk di sebut juga gardu unit pusat beban yang merupakan gabungan dari transformer dan rangkaian switchgear yang tergabung dalamsatu kesatuan melalui sistem kontrol yang saling mendukung untuk keperluan operasional. Pada dasarnya gardu induk bekerja mengubahtegangan yang dibangkitkan oleh pusat pembangkit tenaga listrik menjaditenaga listrik menjadi tegangan tinggi atau tegangan transmisi dansebaliknya mengubah tegangan menengah atau tegangan distribusi.

Gardu Induk juga merupakan sub sistem dari sistem penyaluran (transmisi) tenaga listrik, atau merupakan satu kesatuan dari sistem penyaluran (transmisi). Penyaluran (transmisi) merupakan sub sistem dari sistem tenaga listrik. Berarti, gardu induk merupakan sub-sub sistem dari sistem tenaga listrik. Sebagai sub sistem dari sistem penyaluran (transmisi), gardu induk mempunyai peranan penting, dalam pengoperasiannya tidak dapat dipisahkan dari sistem penyaluran (transmisi) secara keseluruhan.Pengaturan daya ke gardu-gardu induk lainnya melalui tegangan tinggi dan gardugardu induk distribusi melalui feeder tegangan menengah.

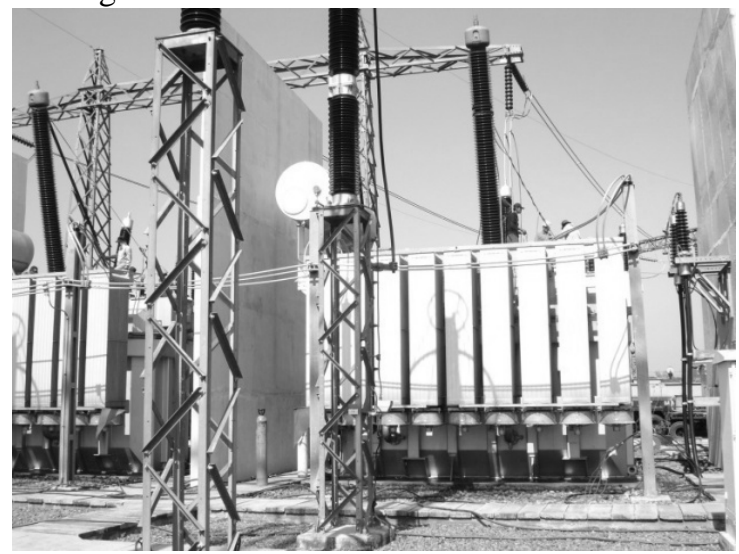

Gambar 1. Gardu Induk

Gardu Induk merupakan sub sistem dari sistem penyaluran (transmisi) tenaga listrik, atau merupakan satu kesatuan dari sistem penyaluran (transmisi). Penyaluran (transmisi) merupakan sub sistem dari sistem tenaga listrik.

\section{Saluran Distribusi Primer}

Terletak pada sisi primer trafo distribusi, yaitu antara titik Sekunder trafo substation (Gardu Induk) dengan titik primer trafo distribusi. Saluran ini bertegangan menengah $20 \mathrm{KV}$. Jaringan listrik $70 \mathrm{KV}$ atau $150 \mathrm{KV}$, jika langsung melayani pelanggan, bisa disebut jaringan distribusi.

\section{Saluran Distribusi Sekunder}

Terletak pada sisi sekunder trafo distribusi, yaitu antara titik sekunder dengan titik cabang menuju beban.

Jaringan distribusi sekunder atau jaringan distribusi tegangan rendah merupakan jaringan tenaga listrik yang langsung berhubungan dengan konsumen. Oleh karena itu besarnya tegangan untuk jaringan distribusi sekunder ini adalah 130/230 V dan 130/400 V untuk sistem lama, atau 380/220 V untuk sistem baru. Universitas Sumatera UtaraTegangan $130 \mathrm{~V}$ dan $220 \mathrm{~V}$ merupakan tegangan antara fasa dengan netral, sedangkan tegangan 400 atau $380 \mathrm{~V}$ merupakan tegangan fasa dengan fasa.

\section{Badan Listrik/Konsumen}

Berdasarkan situs resmi PT. PLN (Persero) (http://www.pln.co.id) pelanggan/ konsumen listrik dibedakan menjadi beberapa kelompok yang dapat dijelaskan berikut ini. 


\section{Pelanggan Rumah Tangga}

Pelanggan tarif Rumah Tangga adalah pelanggan perseorangan atau badan sosial yang tenaga listriknya digunakan untuk keperluan rumah tangga.

\section{Pelanggan Bisnis}

Pelanggan yang termasuk kedalam golongan tarif Bisnis adalah Pelangan yang sebagian atau seluruh tenaga listrik dari PT PLN (Persero) digunakan untuk salah satu atau beberapa kegiatan berbentuk :

- Usaha jual beli barang, jasa, dan pehotelan

- Usaha perbankan

- Usaha perdagangan ekspor/impor

- Kantor Firma, CV, PT atau badan hukum/perorangan yg bergerak dalam bidang usaha perdagangan.

- Usaha pergudangan dimana sebagian atau seluruh bagunan digunakan untuk tempat penyimpanan badang atau material

- Usaha peorangan atau badan hukum yang sebagian besar atau seluruh kegiatannya merupakan penjualan barang atau jasa

- Usaha-usaha lainnya yang bertendensi komersial seperti praktek dokter, dan lain sebagainya.

\section{Pelanggan Industri}

Berbeda dengan aturan Tarif Tenaga Listrik sebelumnya, usaha dengan kegiatan pengolahan yang memberikan nilai tambah atas sesuatu produk, dapat dikeluarkan dari kelompok tarif bisnis dan dimasukkan dalam kelompok Industri. Kebijakan ini diambil demi konsistensi penerapan Klasifikasi Lapangan Usaha Indonesia (KLUI) atau International Standard Industrial Classification of All Economics Activities (ISIC).

\section{Pelanggan Kantor Pemerintahan \& PJU}

Pelanggan yang termasuk kedalam golongan tarif Kantor Pemerintah dan Penerangan Jalan Umum (atau tarif publik) adalah pelanggan yang tenaga listriknya digunakan untuk kegiatan dan kepentingan umum, kepentingan pemerintah, fasilitas kantor perwakilan negara asing.

\section{Susut Distribusi}

Pada dasarnya pengertian tentang kebocoran atau kerugian listrik adalah selisih antara jumlah energi listrik yang di bangkitkan dibandingkan dengan jumlah rekening listrik yang ditangguhkan atau terjual ke pelanggan PLN.

\section{Tegangan Distribusi}

Tegangan untuk jaringan distribusi dapat dibagi menjadi beberapa jenis, antara lain:

- $\quad$ Tegangan Menengah (TM)

Tegangan menengah adalah tegangan dengan rentang nilai $1 \mathrm{KV}$ sampai dengan $30 \mathrm{KV}$.
Untuk di Indonesia menggunakan tegangan menengah sebesar $20 \mathrm{KV}$. Tegangan menengah dipakai untuk penyaluran tenaga listrik dari GI menuju gardu-gardu distribusi atau langsung menuju pelanggan tegangan menengah.

- $\quad$ Tegangan Rendah (TR)

Tegangan rendah adalah tegangan dengan nilai di bawah $1 \mathrm{KV}$ yang digunakan untuk penyaluran daya dari gardu-gardu distribusi menuju pelanggan tegangan rendah. Penyaluran dilakukan dengan menggunakan sistem tiga fasa empat kawat yang dilengkapi dengan netral. Di Indonesia menggunakan tegangan rendah 380/220 V. Dengan $380 \mathrm{~V}$ merupakan besar tegangan antar fasa dan tegangan $220 \mathrm{~V}$ merupakan tengangan fasa netral. Tegangan Pelayanan adalah

$\begin{array}{llrl}0 & 380 / 220 \mathrm{~V} & \text { tiga fasa empat kawat } \\ 0 & 220 \mathrm{~V} & \text { satu fasa dua } \\ & \text { kawat } & & \\ 0 & 6 \mathrm{KV} & \text { tiga fasa tiga kawat } \\ 0 & 12 \mathrm{KV} & \text { tiga fasa tiga } \\ & \text { kawat } & & \\ 0 & 20 \mathrm{KV} & \text { tiga fasa tiga } \\ & \text { kawat } & & \end{array}$

\section{Beban Listrik}

Untuk merencanakan suatu sistem distribusi tenaga listrik maka salah satu hal yang harus diperhatikan adalah beban listrik. Ada beberapa hal yang perlu diperhatikan untuk mengetahui beban listrik tersebut. Pelanggan dapat diklasifikasikan dalam :

- Pelanggan Rumah Tangga

- Industri

- Pelanggan Bisnis

\section{Karakteristik Beban Listrik}

Faktor-faktor yang menentukan karakteristik beban antara lain:

- Faktor Beban (Load Factor)

- Faktor Kebutuhan (Demand Factor)

- $\quad$ Faktor Penggunaan (Utility Factor)

Daya

Daya merupakan faktor penting dalam menentukan besaran energi listrik yang terpakai. Daya disimbolkan P (power). Unsur-unsur yang berpengaruh dalam daya merupakan besarnya tegangan yang bekerja untuk mengalirkan suatu satuan arus selama waktu tertentu. Dalam suatu beban selain kebutuhan oleh besarnya daya aktif juga ditentukan oleh kebutuhan daya reaktif. 


\section{PENGAMATAN}

Dalam pengamatan kali ini, penulis menyertakan alur/ flowchart untuk memudahkan tahapan dalam mengerjakan penelitian.

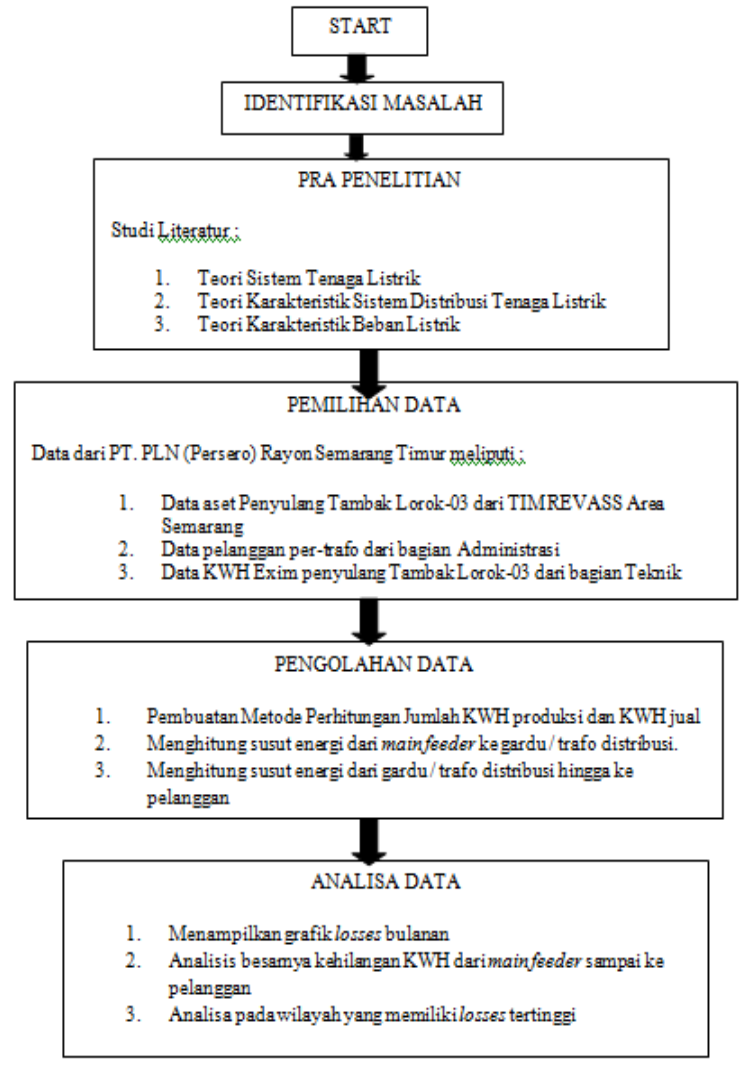

Gambar 2. Alur (Flow Chart) Metodologi Penelitian

\section{HASIL PENGAMATAN DAN PEMBAHASAN Hasil Pengamatan} Pemetaan dan Pendataan Gardu Trafo Distribusi pada Penyulang Tambak Lorok-03

Pemetaan dan pendataan Gardu Trafo Distribusi dimaksudkan untuk pembenahan data aset yang terdapat pada penyulang sehingga memudahkan pencarian serta pengawasannya. Dalam hal ini dilakukan dengan beberapa cara berikut :

\section{- Melakukan survey ke lapangan}

Adalah kegiatan pengecekan dan pencatatan data diawali dengan pembagian form survey ke petugas survey dan dilanjutkan dengan mendatangi lapangan dengan membawa form survey tersebut. Form survey diisi langsung sesuai dengan kondisi dilapangan sehingga kemudian hasil pencatatan akan dilakukan penggambaran dengan menggunakan program MS. Excel.

- Melakukan penggambaran dari entri data hasil survey

Dari sekian banyak form yang terkumpul, maka langkah selanjutnya adalah menggambar jaringan dari feeder tersebut beserta aset yang ada didalamnya dengan menggunakan MS.
Excel. Hal ini dilakukan demi pembenahan data jaringan khususnya penomoran pada tiang yang baru serta terdeteksinya jumlah trafo yang benar-benar ada dilapangan.

- Komparasi data hasil survey dengan data trafo lama

Sesuai hasil survey jumlah trafo $\quad=152$ trafo (1 phasa dan 3 phasa)

Sesuai data trafo lama

trafo (1 phasa dan 3 phasa)

Selisih

trafo

Ada beberapa hal yang mengakibatkan selisih antara data survey dan data yang telah ada, salah satunya yaitu tidak ter-update nya data trafo yang telah dilakukan penggantian maupun yang sudah tidak digunakan.

\section{Perhitungan Rata-Rata Kerugian Komersial Penyulang Tambak Lorok III dengan Menggunakan Simulasi ETAP \\ Setelah mendapatkan data trafo serta} panjang jaringan dari hasil survey di lapangan, maka langkah selanjutnya yaitu melakukan analisa aliran daya dengan bantuan Aplikasi Program ETAP. Pengerjaan program ETAP ini dilakukan pada jaringan Tegangan Menengah atau pada batas terpasangnya trafo distribusi. Untuk beban di pelanggan tidak diperhitungkan. Langkah-langkah yang dilakukan antara lain :

- Pengerjaan Program ETAP

- Perhitungan Losses ETAP Berdasarkan Report Manager

- Data Rupiah Losses

- $\quad$ Top Ten Lokasi dengan Losses Tertinggi

Rekonsiliasi Energi KWH Kirim dengan KWH Terima pada Penyulang Tambak Lorok - 03

Salah satu tahapan pada REVASS adalah pencocokan energi dari hilir sampai hulu, atau biasa disebut dari KWH kirim sampai dengan pelanggan. Dimana KWH yang dikirimkan ke suatu penyulang merupakan jumlah besaran dari pengukuran KWH incoming trafo Gardu Induk, sedangkan untuk $\mathrm{KWH}$ yang diterima merupakan $\mathrm{KWH}$ yang dipakai pelanggan di penyulang tersebut.

- Perhitungan KWH pada sisi incoming penyulang Tambak Lorok - 03

- $\quad$ Perhitungan KWH pelanggan TM > 200 KVA

- Perhitungan KWH pelanggan TR

- $\quad$ Perhitungan Losses KWH pada Penyulang

\section{Pembahasan}

Berdasarkan hasil pengamatan diatas, maka dapat ditarik suatu jawaban dari rumusan masalah yang telah ditulis pada bab sebelumnya yaitu :

- Besar Losses Teknis dan Non-Teknis dalam $\mathrm{KWH}$ 
- Besar Kerugian Losses Teknis dan NonTeknis Dalam Rupiah

- Besar Prosentase Losses dari Teknis Maupun Non-Teknis

- Hal-hal Penyebab Losses

- Rencana Langkah - Langkah Perbaikan

\section{KESIMPULAN DAN SARAN}

Kesimpulan

- Berdasarkan penataan data trafo distribusi yang telah dilakukan maka terdapat selisih antara data trafo yang tertera dengan hasil survey yang telah dilakukan yaitu sebanyak 49 trafo.

- Berdasarkan perhitungan kerugian akibat losses di jaringan dalam nominal rupiah, yaitu dengan metode mencari selisih antara KWH kirim (outgoing trafo Gardu Induk) dan terima (konsumsi pelanggan) maka dalam satu bulan total kerugian susut energy dalam rupiah adalah sebesar Rp. 2.500.000.000,-.

- Losses pada jaringan Tegangan Menengah feeder Tambak Lorok - 03 yang disimulasikan dengan program aplikasi ETAP dapat diasumsikan sebagai losses teknis yaitu sebesar 16.281 KWH atau secara komersial sebesar Rp. 30.150.000,-.

- Dari perhitungan kerugian susut energy dengan metode selisih KWH kirim dan terima per-bulan dalam rupiah kemudian dikurangkan dengan rata-rata kerugian teknis per-bulan, maka besarnya losses non teknis pada jaringan adalah sebesar bekisar 0,7\% dari besaran susut secara keseluruhan.

- Berdasarkan losses kumulatif yang di dapat dari program aplikasi ETAP, dapat diidentifikasi 10 lokasi yang mempunyai susut tertinggi secara teknis.

- Penyebab susut secara teknis antara lain:

o Kriteria desain yang kurang akurat

o Konstruksi pada jaringan yang tidak sesuai

o Mutu material yang buruk

o Kurangnya pemeliharaan pada jaringan

- Penyebab susut secara non-teknis antara lain:
o Pencurian listrik
o Kesalahan pencatatan meter
o Administrasi

\section{Saran}

- Untuk menurunkan angka losses pada Penyulang Tambak Lorok-03 berdasarkan simulasi aplikasi ETAP maka diperlukan penambahkan feeder maupun jaringan baru (bus) untuk memperkecil arus pada area yang memiliki losses tinggi.

- Dalam rangka menurunkan losses berdasarkan program rekonsiliasi energy ini, perlu dilaksanakan program perbaikan secara terstruktur dengan skala yang besar sebagai upaya menjamin kesesuaian jumlah energi yang dikirim dengan energi yang diterima di pelanggan serta menekan piutang perusahaan terhadap pelanggan.

- Berdasarkan perhitungan yang telah dilakukan, upaya penekanan dapat dilaksanakan pada sisi non teknis terlebih dahulu, dikarenakan susut secara non-teknis menyumbang lebih dari 90\% dari jumlah susut secara keseluruhan. Khususnya dengan melaksanakan P2TL, penertiban PJU liar, serta penertiban administrasi secara intens.

\section{DAFTAR PUSTAKA}

1. Anonim. 2011. Deployment Revenue Assurance (RA). PLN - DJBB: Jatiluhur.

2. Anonim. 2012. SOP Rekonsiliasi Energi. PT. PLN (Persero).

3. Anonim. 2013. Gardu Induk. PT. PLN (Persero). $\quad$ http://pln.co.id/uiptet/?p=672. Diunggah tanggal 17 Juni 2013.

4. Anonim. 2013. Definisi Pelanggan Listrik. PT. PLN (Persero).

5. Aprieta, Nindya. 2009. Prototipe Pemetaaan Losses Teknis Per Lokasi Trafo Feeder Dahlia Dan Teratai Yang Berbasis PDPJ. Pekanbaru.

6. Chapman, Stephen J. 2002. Electric Machinery and Power System Fundamentals International Edition, Mc Graw Hill. Singapore.

7. Rahmadhianto, Danang. 2008. Studi Susut Energi pada Sistem Distribusi Tenaga Listrik Melalui Analisis Pengukuran dan Perhitungan.. FT UI : Jakarta.

8. Susanto, Daman. 2012. Sistem Distribusi Tenaga Listrik. Jakarta, Materi 9 dan Materi 12. 